La Revue

des Droits

de l'Homme

\section{La Revue des droits de l'homme}

Revue du Centre de recherches et d'études sur les droits fondamentaux

$2 \mid 2012$

Revue des droits de l'homme - $\mathrm{N}^{\circ} 2$

\title{
Entretien avec Martine Lombard
}

Membre du Conseil supérieur de la Magistrature, professeure de droit public à l'université de Paris II - Panthéon-Assas

\section{Charlotte Girard}

\section{OpenEdition}

\section{Journals}

Édition électronique

URL : http://journals.openedition.org/revdh/182

DOI : $10.4000 /$ revdh. 182

ISSN : 2264-119X

\section{Éditeur}

Centre de recherches et d'études sur les droits fondamentaux

\section{Édition imprimée}

Date de publication : 1 décembre 2012

\section{Référence électronique}

Charlotte Girard, «Entretien avec Martine Lombard », La Revue des droits de l'homme [En ligne], 2 |

2012, mis en ligne le 27 novembre 2013, consulté le 08 juillet 2020. URL : http://

journals.openedition.org/revdh/182 ; DOI : https://doi.org/10.4000/revdh.182

Ce document a été généré automatiquement le 8 juillet 2020.

Tous droits réservés 


\title{
Entretien avec Martine Lombard
}

\author{
Membre du Conseil supérieur de la Magistrature, professeure de droit \\ public à l'université de Paris II - Panthéon-Assas
}

\section{Charlotte Girard}

1 Le rapport public 2011 du Conseil supérieur de la Magistrature révèle que si les femmes constituent la grande majorité de la magistrature judiciaire ( $80 \%$ des reçus au concours de l'ENM sont des femmes), elles n'occupent qu'une faible part des postes les plus importants hiérarchiquement. Sur la tranche d'âge de plus de 65 ans, seules $35 \%$ des femmes sont hors hiérarchie, contre $55 \%$ des hommes. Chez les 60 à 64 ans, $37 \%$ des femmes restent hors hiérarchie, contre $51 \%$ des hommes. Entre 55 et 59 ans, $14 \%$ des femmes demeurent hors hiérarchie, contre $26 \%$ des hommes. Cette réalité se concrétise du côté des chefs de juridiction. Seules cinq femmes sur les cinquante-quatre premiers présidents de cour d'appel et cinquante sur les cent quatre-vingt-quinze présidents de tribunaux de grande instance ont été nommées entre 2007 et 2011 . Pour ce qui concerne le Parquet, une seule femme sur neuf procureurs généraux a été nommée en 2011. Et on ne compte que trente-huit femmes parmi les cent quatre-vingtdix-sept procureurs de la République nommés de 2006 à 2011. Face à un tel constat, le CSM a pris la résolution de... "faire quelque chose ». Martine Lombard, qui en est membre, lève un pan du voile.

La question de la place des femmes dans la magistrature est enfin posée dans le dernier rapport public d'activité du Conseil supérieur de la Magistrature. S'il est manifeste que les femmes y sont aujourd'hui majoritaires, il est également manifeste qu'elles sont sous-représentées aux postes "hors hiérarchie ». Comment expliquez-vous cette situation?

Le dernier rapport public d'activité du Conseil supérieur de la magistrature n'a pas l'originalité qu'il serait possible de lui prêter. Cela fait en effet plusieurs années qu'une rubrique consacrée à la place respective des hommes et des femmes dans la magistrature, comportant pour ce faire des statistiques par sexe, figure dans les rapports d'activité du CSM. Ce n'est d'ailleurs pas très original au regard des pratiques courantes concernant, par exemple, la réussite aux concours d'entrée à l'École nationale d'administration ou, d'une façon plus générale, concernant la haute fonction publique. À ce stade, nous avons simplement constaté que les chances d'accès des femmes aux postes "hors hiérarchie » ou aux emplois de chef de 
juridiction étaient sensiblement inférieures à celles des hommes, même à tranche d'âge identique, sans que l'âge moyen respectif des uns ou des autres puisse donc expliquer ces différences. Nous n'avons pas encore répondu à la question de savoir pourquoi un tel phénomène se produisait, et c'est précisément ce sur quoi nous devons réfléchir, avant de tenter, dans toute la mesure du possible et du nécessaire, d'y apporter éventuellement remède.

Croyez-vous que le recours à des statistiques par sexe comporte un risque d'atteinte au principe d'égalité, ainsi qu'à la neutralité de la fonction publique?

Pour repérer s'il existe des différences, voire des discriminations et tenter, dans ce cas, d'y remédier, il paraît en effet d'abord utile, voire nécessaire, d'en prendre la mesure éventuelle à travers des relevés statistiques.

Vous-même êtes l'une des huit femmes membre d'une éminente institution de la République, le Conseil supérieur de la Magistrature qui compte vingt-quatre membres (secrétariat général inclus). Croyez-vous qu'un dispositif susceptible d'y favoriser l'égal accès des femmes comme dans d'autres institutions politiques ou professionnelles soit souhaitable et/ou envisageable? Pensez-vous d'ailleurs que le fait de promouvoir la nomination de femmes aux postes dits hiérarchiques ou, d'une manière générale, dans la haute fonction publique s'analyse de la même manière et appelle le même type de mesures que pour les mandats politiques?

Notre souci prioritaire est en effet d'éviter des discriminations et, pour ce faire, d'en rechercher toutes les sources possibles, et d'y remédier, avant même de songer à des «discriminations positives » et autres mesures plus volontaristes. Un groupe de travail associant magistrats et non magistrats a été constitué pour approfondir ces questions et proposer des remèdes, qui seront soumis à l'ensemble du CSM. Nous verrons alors s'il faut modifier en profondeur les « règles du jeu » pour parvenir à un meilleur équilibre ou si une prise de conscience peut suffire à y contribuer. 